\title{
Reflexiones bioéticas acerca de la ancianidad desde el estoicismo de Séneca
}

\section{Bioethical reflections on the old age from the stoicism of Seneca}

\author{
José Enrique Gómez Álvarez*
}

https://doi.org/10.36105/mye.2020v31n1.01

\section{Resumen}

El artículo expone cómo el análisis de ciertas obras de Séneca nos muestra a un pensador que concibe la vejez como un estado digno de vivirse. La vejez, tal como la concibe Séneca, puede ser valiosa y sabia, o no, pero no existen características negativas inevitables o "esenciales» de la vejez como las presenta, por ejemplo, Aristóteles. Para lograr lo anterior, en la primera sección se expone el concepto de «vejez» como decadencia, tal como se concibió en ocasiones en la antigüedad griega y romana. En las secciones 2 a 5, utilizando dos categorías estoicas presentadas por Séneca -la relatividad del tiempo y el sometimiento a la razón-, en combinación con temas clave de una ética de la vejez -el trabajo, la muerte, la finitud y la autonomía-, se estudia el valor de la vejez en la obra de este autor. En las conclusiones se expone que el estudio de los textos muestra que Séneca considera la vejez como digna y valiosa en sí misma; que se mantiene en los ámbitos de la razón, y que defiende que la vejez no es necesariamente decadencia de las personas.

\footnotetext{
* Doctor en Filosofía por la Universidad de Navarra. Maestro en Gerontología Social. Profesor e investigador del CISAV. https://orcid.org/0000-0002-8964-220

Correo electrónico: jegomezalvarez@yahoo.com

Recepción: 04 de noviembre de 2019. Aceptación: 30 de noviembre de 2019.
} 
Palabras clave: vejez, autonomía, razón, suicidio, muerte.

\section{Introducción: la vejez como decadencia}

Es conocido que, en la antigüedad clásica en general, existía la tendencia a asociar vejez con enfermedad. ${ }^{1}$ La enfermedad era entendida no sólo como una afección temporal, sino como constitución esencial de la vejez. En pocas palabras, algunos afirmaron que el envejecimiento era una enfermedad en sí misma. ${ }^{2}$

No obstante, aquí interesa reflexionar, más que sobre la patología del anciano, sobre la caracterización moral/mental del mismo. Lo anterior con el objetivo de extraer directrices pedagógicas y éticas sobre la ancianidad: el valor y el modo de comportarse en la misma, según la óptica de Séneca. ${ }^{3}$ Para lo anterior, se toma a Aristóteles como el punto de partida a partir del texto de la Retórica, y de ahí se establece la visión pesimista de la vejez y la caracterización que le da el Estagirita. La caracterización anterior se contrasta con la valoración y ciertos juicios sobre la vejez de Séneca, para matizar, así, la postura negativa de la vejez como periodo de vida.

A diferencia de las épocas arcaicas, cuando el anciano era concebido como un pilar de sus comunidades, en las sociedades clásicas griegas ya no aparece esa misma visión o, al menos, aparece una visión de la vejez como decadencia de la vida. La vida es vista como una secuencia, en la que se da un punto culminante o acmé (periodo de mayor intensidad de una enfermedad), a partir del cual posteriormente se produce el decaimiento de la existencia.

Aristóteles describe la vejez como el estado del hombre opuesto a la juventud o, dicho de otro modo, dentro de su teoría del término medio, el anciano se constituye como el defecto, mientras que el polo opuesto, el exceso, es el carácter del joven. En Retórica (II, 12, 1389b, p. 15 y ss.), Aristóteles describe el carácter de los viejos con categorías bastante negativas: el anciano no pone el empeño debido en las cosas; cree, sin asegurar con firmeza; es de mal carác- 
ter, ya que supone lo peor de las cosas; es, asimismo, receloso; no desea más que lo esencial para vivir; es mezquino, cobarde, desvergonzado, pesimista, esclavo del interés, charlatán, quejumbroso y compasivo, pero por debilidad. ${ }^{4}$

En el periodo romano también se presenta un pesimismo acerca de la ancianidad. Según Gracia:

El viejo no interesa mucho, porque se le considera un sujeto enfermo; en tanto enfermo, feo y malo... Desde esta perspectiva es desde la que hay que leer los tratados $D e$ senectute escritos en la época clásica... No se crea que en ellos se alaba la vejez. Todo lo contrario. De lo que se trata es de aceptar estoicamente los achaques de la ancianidad, de sobrellevarlos con paciencia, y de sacar de ellos el mejor partido posible. ${ }^{5}$

En este ensayo se propone que estas características pueden interpretarse de una manera matizada desde la óptica del estoicismo de Séneca. Se sugiere, así, releer las características de la vejez como las presenta este filósofo y valorar si podrían interpretarse como verdaderas virtudes desde el punto de vista estoico. O, en otras palabras, entresacar de los textos de Séneca los aspectos valiosos de la vejez y que se alejan de las características negativas indicadas por Aristóteles y durante el periodo clásico antiguo en general. Para ello, la descripción de la vejez se centra en las Cartas a Lucilio, ${ }^{6}$ ya que éstas poseen temas específicos referidos a la vejez. Lo anterior se complementa con referencias a otras obras filosóficas del mismo autor. ${ }^{7}$

\section{Categorías para el análisis de los escritos de Séneca}

Se puede mostrar que en Séneca se encuentran muchos comentarios pesimistas o, quizás, diríamos «realistas» acerca de la naturaleza debilitada del cuerpo en la vejez. Aunque, como se espera mostrar 
en el escrito, la vejez no se presenta como decadente en sí misma, a pesar de que sí se hacen señalamientos acerca de la realidad finita del hombre en el horizonte del final de su vida.

En general, las observaciones de Séneca están dispersas a lo largo de las Cartas. Algunas de ellas, no obstante, tratan el tema casi en específico: las Cartas XII, XXVI, LXI, XCIII, XCVI. En prácticamente todas ellas se encuentra el principio práctico del estoicismo; de que lo que afecta más nuestra existencia es la opinión que se tiene de las cosas, más que las cosas en sí mismas, entre ellas la vejez (ver Tabla 1). Este principio regula muchas de las respuestas en torno a la vejez y sus dolencias.

\begin{tabular}{|c|c|}
\hline Carta & \multicolumn{1}{c|}{ Ideas centrales } \\
\hline XII & $\begin{array}{l}\text { La vida es una serie de ciclos. Hay que agradecer cada día de } \\
\text { vida que Dios ha dado. No es forzoso permanecer vivo. }\end{array}$ \\
\hline LXI & $\begin{array}{l}\text { La vejez puede ser decrépita. La vejez pierde fuerza, pero si se } \\
\text { acomoda uno a la naturaleza, se percibe diferente el proceso. } \\
\text { Hay que aprender a morir. }\end{array}$ \\
\hline XCIII & $\begin{array}{l}\text { Cada día debe tomarse como si fuera el último. No hay que de- } \\
\text { hay que vivir bien y, de anciano, morir bien. }\end{array}$ \\
$\begin{array}{l}\text { Hay que obedecer a la naturaleza. Se debe vivir bien y no mucho } \\
\text { tiempo: «De qué le sirven a uno ochenta años si los pasa en la } \\
\text { inercia? No vivió éste, sino que se detuvo en la vida; ni murió } \\
\text { tarde, sino durante mucho tiempo. Vivió ochenta años». El vivir } \\
\text { no equivale a la duración. El vivir es el ser, mientras que la dura- } \\
\text { ción es ajena a nosotros. Vivir hasta la sabiduría es la meta. }\end{array}$ \\
\hline XCVI & $\begin{array}{l}\text { El que desea la vejez desea las cosas que vienen con ella. Las } \\
\text { cosas duras y adversas se aceptan como decretadas por Dios. La } \\
\text { vida es una guerra. }\end{array}$ \\
\hline
\end{tabular}

Puede realizarse un análisis desde los propios conceptos estoicos para mostrar esa doble faceta de la vejez: a veces se muestra con 
crudeza la debilidad propia de la edad, pero se puede vivir y debe vivirse acorde con la sabiduría que sabe realizar el juicio correcto de las cosas, poniéndolas en su justo valor. El juicio recto sobre las cosas aplica a cualquier etapa de la vida, incluida la vejez.

Ahora bien, este contraste entre vejez como deplorable y como etapa valiosa en sí misma aparece en muchos pasajes de su obra. Por ejemplo, en la Carta XII, Séneca comienza lamentándose de las condiciones ruinosas de una propiedad suya, de las plantas de su finca y del estado físico deplorable de un amigo suyo. El tono es de cierta amargura ante las situaciones del deterioro de su ambiente y amigos, pero, de repente, Séneca afirma respecto de la vejez: «abrecémonos a ella y amémosla; llena está de placer si la sabemos usar». ${ }^{9}$ Por supuesto, la frase puede leerse en un tono amargo, «ya que la vejez de cualquier forma llega, pues tomémosla con buen sentido». No obstante, la frase da a entender que, en realidad, la vejez es digna en sí misma cuando señala: «En todo placer lo más agradable es lo que está al final». ${ }^{10}$

Lo anterior se refuerza en otra de sus Cartas. Señala que él ya está en la decrepitud, aunque «el ánimo está vigoroso»; ${ }^{11}$ o sea, de nuevo el juicio acerca de la misma. En la Consolación a la madre Helvia, Séneca, al hacer alusión a las inevitables emigraciones humanas, señala: «En esas emigraciones se dejaban arrastrar hasta las mujeres, los niños y los viejos agobiados por el peso de la edad». ${ }^{12}$ De nuevo no es una descalificación, sino un cierto reconocimiento de que a los viejos les tocan también diversas situaciones como a la gente joven, pero asumiendo las limitaciones de la edad.

Séneca, como buen estoico, defiende el papel del buen juicio frente a los acontecimientos, como se muestra en los fragmentos anteriores. Además, el universo está regido por Dios, quien pone el hado que rige nuestra existencia:

Por lo cual conviene sufrir todos los sucesos con fortaleza, porque no todas las cosas suceden como pensamos; vienen como está dispuesto, y si desde sus principios está así ordenado... ¿Qué cosa es propia del 


\section{J. E. Gómez Álvarez}

varón bueno? Rendirse al hado, por ser grande consuelo el ser arrebatado con el universo (De Providencia, $V$ ). ${ }^{13}$

Naturalmente, el ser anciano no excluye de esa actitud ante la vida, aun en circunstancias como la pérdida de los bienes y el estar en soledad (De la constancia del sabio, VI). ${ }^{14}$ Es una verdadera pedagogía ante la vejez. Como resume Iacub:

Séneca consideraba que lo malo nunca estaba tan incrustado en el hombre como para que no pudiera ser modificado... Esta preparación implicaba que el hombre debía realizar un cambio, un aprendizaje sostenido desde la crítica y la reflexión sobre sí mismo. Séneca extremó esta idea hasta el punto de convertir la vejez en un objetivo positivo de la existencia, polarizando con sus propios valores todo el curso de la vida. ${ }^{15}$

Otra categoría estoica de análisis la podríamos denominar como «relatividad del tiempo». El tiempo cronológico no es crucial, sino el tiempo vivido con sensatez: «El tiempo que tenemos no es corto; pero perdiendo mucho de él, hacemos que lo sea, y la vida es suficientemente larga para ejecutar en ella cosas grandes, si la empleásemos bien» (De la brevedad de la vida, I). ${ }^{16}$

Adicionalmente, para clasificar el análisis se pueden agrupar las ideas de los textos de Séneca en:

...cuatro problemas filosóficos ante los que no puede pasar por alto una ética de la ancianidad: la finitud, el trabajo, la autonomía y la muerte... Un tiempo vivido desde el que no nos resignamos a pensarnos mortales... La finitud... la ancianidad nos despierta para una vida moral menos perfecta y todopoderosa... Esta adaptación, acaso estoica, se presta a infinitud de matices... gozosa, resignada o melancólica... ${ }^{17}$

Tomando estas categorías de la muerte, la finitud, el trabajo y la autonomía sugeridas por Domingo y las dos tomadas de Séneca - la aceptación del destino usando la razón y la relatividad del tiempo-, pasemos a analizar otras facetas de la ancianidad según Séneca. 
Reflexiones bioéticas acerca de la ancianidad desde el estoicismo de Séneca

\section{La ancianidad y la muerte}

Me parece, quizás pensando de modo optimista, que, para Séneca, como puede vislumbrase en lo ya señalado, la vejez tiene cierto aire de derrota ante la vida, pero, por otra parte, considera que la misma no sólo se sobrelleva, como señalaba Gracia, sino que realmente aporta algo al devenir propio de la existencia.

Una idea reiterativa en Séneca es que hay que aprender a morir o prepararse para la muerte (De la brevedad de la vida, VII) ${ }^{18} \mathrm{La}$ vida debe considerarse entre las cosas serviles y no debe evitarse el aprender a morir bien (De la tranquilidad del alma, II). ${ }^{19}$ La vejez, entonces, es reconocer la valía de la persona en sí misma. De acuerdo con la propuesta de Séneca, esa preparación para la muerte implica que el tiempo que transcurre hacia la misma no se reduce a lo cronológico. El tiempo realmente vivido, si está dirigido a la virtud, es percibido como abundante, mientras que gastado en frivolidades lo convierten en perdido. La muerte aparece como un límite que se afronta con sentido, aceptándolo a la vez, pero preparado en un devenir que lo tiene siempre presente.

Por otra parte, Séneca señala que siempre está la opción del suicidio: «Agradezcamos a los dioses que nadie pueda ser obligado a vivir». ${ }^{20}$ Sin embargo, en las mismas Cartas, cuando aborda el tema específico del suicidio, de ningún modo lo delimita a la vejez, sino a cualquier circunstancia en donde se viva una vida indigna: «...que quede bien claro que ha de preferirse la muerte más sucia a la servidumbre más limpia». ${ }^{21}$ Claro que esta última referencia encaja con la idea estoica de vivir de acuerdo con la razón. El suicidio no es lícito por el capricho o la desesperanza, sino por una decisión en donde se afirma la dignidad del que lo ejecuta. Nótese así que Séneca no ve la vida como un valor absoluto, sino el vivir de acuerdo con la razón. En suma, la vejez no constituye en sí misma una cualidad particular para el suicidio. Aunque pueda parecer un aire de derrota ante la vida, Séneca cree que un suicidio «adecuado» le da sentido a la existencia. Es, como señala Domingo: «Cuando 
hablamos de muerte personal, muerte propia o muerte digna, queremos expresar la necesidad que tenemos de que la muerte sea una ejercitación de la libertad, un acto biográfico con el que responder a un hecho biológico». ${ }^{22}$ Así, Séneca no ve el suicidio como «una salida fácil», sino como una salida digna cuando las circunstancias de la vida lo exigen así. Claro que es una decisión personal y dependerá de cada caso, pero en sí misma no se determina por la edad de la persona como tal, sino por su situación existencial, por decirlo así.

El criterio para seleccionar la muerte, en caso de que sea un poder externo el que amenace a la persona, es lícito acelerar y/o adelantar la muerte. El criterio parece ser, más bien, sobre «si la muerte es con tormentos y la otra es sencilla y fácil, ¿por qué no echar mano de ésta?» ${ }^{23}$ En suma, la decisión es estrictamente personal, aunque un elemento a considerar es que la muerte no sea la más larga. Así, la situación de la vejez como dolorosa y llena de incomodidades no nos obliga a vivirla, ya que puede optarse por dejar la vida. Hay que recordar que el tiempo vivido en cuanto duración no es el valor, sino el cómo se ha vivido y si se ha dirigido a la sabiduría. $^{24}$

No obstante, puede haber razones para no quitarse la vida, aunque se quiera. Una razón son los efectos en las otras personas. Así, Séneca señala que no se suicidó cuando su padre vivía, porque éste no hubiera soportado la ausencia suya. De lo cual podemos quizás deducir que, mientras no se afecte desproporcionadamente a los demás, puede permitirse el suicidio.

De cualquier forma, no hay que tenerle miedo a la muerte. No es como tal ni buena ni mala. ${ }^{25}$ Aunque Séneca aclara: «La muerte está entre las cosas que no son malas, pero tienen la apariencia de mal». ${ }^{26} \mathrm{El}$ amor propio y el instinto de conservación es lo que produce la apariencia de pérdida ante la muerte. Además, la ignorancia sobre cómo es el morir hace temerla. Hay que tener un espíritu virtuoso para saber enfrentarse a la muerte. 
Reflexiones bioéticas acerca de la ancianidad desde el estoicismo de Séneca

Entonces, no es una aspiración necesaria el tener una larga vida, sino una vida coherente y plena:

¿De qué le sirven a uno ochenta años si los pasa en la inercia? No vivió éste, sino que se detuvo en la vida; ni murió tarde, sino durante mucho tiempo: vivió ochenta años. Pero interesa saber desde qué día cuenta su muerte... Vivió ochenta años. Mejor, duró ochenta años, a no ser que se diga de él que vivió como viven los árboles... La edad está entre las cosas externas. Cuánto he de vivir, es cosa ajena; lo que he de ser mientras exista, es cosa mía. ${ }^{27}$

En pocas palabras, es importante vivir bien, no importando la duración en el tiempo. Tener la muerte enfrente no es propio de la vejez, sino de toda la vida. La vida se vive día a día, y en eso la vejez no es diferente de la juventud.

\section{La finitud y la enfermedad}

Ya se han hecho referencias a pasajes que conectan la vejez con la pérdida de funciones y fuerza. Séneca hace alusiones a las situaciones de enfermedad. En todas hace énfasis en cierta resignación, pero también hace alusiones a que la sabiduría y el obrar recto se deben practicar en cualquier edad y dan sentido a la vida. Así, Séneca rechaza la idea aristotélica que se mencionó al comienzo: el viejo como pusilánime y con opiniones poco firmes.

De hecho, la enfermedad nos muestra nuestra limitación. La enfermedad muestra un elemento de la vida que no controlo, pero sí controlo la opinión acerca de la misma: «...en todas las cosas duras y adversas me comporto, no como si obedeciera a Dios, sino como si estuviera de acuerdo con Él»». ${ }^{28}$ Las enfermedades de la vejez se aceptan como acompañantes esperados de la vejez.

La percepción del tiempo es relativa al juicio, no a un tiempo absoluto. Así, para un niño las molestias se perciben largas. El que vive mucho no necesariamente tiene una ventaja sobre el que falle- 
ce joven. Es minúscula la vida humana en relación con la eternidad. La mayor parte del tiempo nos la pasamos en preocupaciones mundanas, además de que dormimos la mitad del tiempo. Morir joven: «¿quién no le concederá que le va mejor a quien se le permite volver pronto que al que terminó el camino antes de que se cansara? La vida no es ni un bien ni un mal; es el lugar del bien y del mal» ${ }^{29}$

La vejez, quizás, no sea enfermedad, pero oprime (De la brevedad de la vida, IX). ${ }^{30}$ En la sección del tiempo se señaló que el estar siempre ocupados hace que el tiempo se pierda, y si lo dedicamos a la virtud y a la reflexión, el hombre sabio, al tener una vida con sentido, no se perturbará por la aparición de la muerte. En cambio, los hombres que se ocupan en menesteres distintos les alcanza la vida en un instante y ahí sí la vejez se ve como tormento:

Mendingan los viejos decrépitos, a fuerza de votos, el aumento de algunos pocos años. Fíngense de menor edad y lisonjéanse con la mentira, engañándose con tanto gusto como si juntamente engañaran a los hados...; mueren como atemorizados, no como los que salen de la vida, sino como excluidos de ella. Dicen a voces que fueron ignorantes en no haber vivido, y que, si escapan de aquella enfermedad, han de vivir en descanso ${ }^{31}$ (De la brevedad de la vida, $X I$ ).

Lo anterior nos lleva a reconocer que el cuidado del alma es lo central y que los cuidados del cuerpo implican no vivir para el cuerpo, sino «como quien no puede vivir sin el cuerpo». ${ }^{32}$ En la vejez, así, no hay diferencia: si se vivió mal, la llegada de la vejez es horrible; pero si se vivió adecuadamente, se asume bien.

\section{La autonomía y el trabajo}

No existe el término «autonomía» como tal en la obra de Séneca, pero pueden encontrarse algunas ideas de la autodeterminación y la vejez. Una de ellas, y que aparece en los escritos, es que nunca 
debe renunciarse al estudio de la filosofía en cualquier edad. Esa aspiración a la racionalidad es meta de todos los hombres: «En cada cosa lo mejor ha de ser aquello para lo que nació, por lo cual se valora. ¿Qué es lo mejor en el hombre? La razón...; la razón es su bien propiom. ${ }^{33}$

Séneca rechaza la idea de que se haya de «dejar al final» de la existencia el ejercicio de la virtud. No deja de utilizar, eso sí, un carácter despectivo de la vejez:

Oirás decir a muchos que, en llegando a cincuenta años, se han de retirar a la quietud, y que el de sesenta jubilará todos los oficios y cargos. Dime, cuando esto te propones, ¿qué seguridad tienes de más larga vida?... ¿No te avergüenzas de reservarte para las sobras de la vida, destinando a la virtud sólo aquel tiempo que para ninguna cosa es de provecho? (De la brevedad de la vida, III). ${ }^{34}$

La filosofía ordena la vida y da las pautas para vivir adecuadamente. El deber del filósofo y de cualquier hombre es eliminar los deseos vanos. Esto aplica, en consecuencia, en cualquier etapa de la vida. En este sentido, cuando en la ancianidad alguien opina con cautela, no debe entenderse como una actitud pusilánime de la ancianidad. En cualquier momento de la vida se debe actuar de forma prudente. Así, en la óptica estoica, el «creer sin asegurar con firmeza» no es en automático un defecto de los ancianos. Los ancianos y todos los hombres, señala Séneca, salen peor de la vida de como entraron, pero no es producto de la edad, sino de las pasiones, temores y supersticiones.

Como buen estoico, Séneca insiste en que la percepción, o mejor el juicio, marca la diferencia: «...el recto y entero corrige las maldades de la fortuna y suaviza lo duro y lo áspero con el arte de sobrellevarlo, de modo que recibe lo favorable con gratitud y modestia, y lo adverso con constancia y fortaleza». ${ }^{35}$

La autonomía, pues, no es controlar el destino, sino aceptarlo con entereza, como se señaló ya en las otras secciones. Pero no es una aceptación «pasiva» del fluir del tiempo, sino un enfrentarse 
continuamente con el mal y vencerlo con base en el esfuerzo diario, lo que garantiza una conciencia tranquila al reflexionar sobre su pasado (De la brevedad de la vida, XII). ${ }^{36}$

Cómo ya se anotó antes, el hombre puede decidir sobre su muerte para evitar el sufrimiento, pero en general el hombre sabio vive con tranquilidad: «Los griegos llaman a esta firmeza del ánimo estabilidad... y yo la llamo tranquilidad» (De la tranquilidad del alma, II). ${ }^{37}$

La verdadera ocupación humana es la sabiduría, la cual proporciona la verdadera quietud y tranquilidad en la vida y es benéfica en todas las edades (De la brevedad de la vida, XIV). ${ }^{38}$ Sin embargo, Séneca aclara que no es el discutir cuestiones eruditas, como cuántos remeros tuvo Ulises, qué se escribió primero, si la Ilíada o la Odisea y temas semejantes. ${ }^{39}$

La sabiduría es la de los filósofos, y ahí sí la vejez no es negativa: «QQué felicidad y qué honrada vejez (pulchra senectus manet) espera al que se puso bajo de la protección de ésta!» (De la brevedad de la vida, XV). ${ }^{40}$ Séneca no duda: ahí la vejez sí tiene un sentido, mientras que las otras ocupaciones sólo marchitan la vida.

El anciano o, mejor dicho, al ser los hombres guiados por las apariencias y la fama, y no según la naturaleza, se vuelven codiciosos e interesados y, así, la avaricia, como otro de los defectos señalados por Aristóteles, no es exclusivo de los ancianos. Séneca, es verdad, no es optimista respecto del aspecto «práctico» de la codicia humana: «Si cambian sus testamentos los viejos solitarios, los que vienen a saludarlos llamarán a otra puerta». ${ }^{41}$

La autonomía consiste, en suma, en el juicio racional sobre la naturaleza de las cosas. Eso no quiere decir que Séneca no viera las miserias de la vida, pero el sentido de las posesiones, por ejemplo, está en el control del deseo: «Porque es pobre no el que tiene poco, sino el que desea más». ${ }^{42}$

Lo anterior nos da pistas acerca del trabajo: Séneca piensa que no debemos llevarnos por las ocupaciones de la vida y perdernos en ellas. Ya se ha señalado que el camino verdadero es la sabiduría. 
La ocupación en la vejez, el trabajar hasta el final, no le parece sensato a este filósofo: «Torpe es aquél a quien, estando en edad mayor, coge la muerte ocupado en negocios..., y torpe aquél que, antes cansado de vivir que de trabajar, murió entre sus ocupaciones (De la brevedad de la vida, XX). ${ }^{43}$

El trabajo es necesario, pero sólo tiene sentido si está supeditado, como ya se dijo, a la razón y a la búsqueda de la sabiduría.

\section{Conclusiones}

Se mencionaba al comienzo del artículo que Gracia indicaba que la percepción estoica de la vejez es la resignación. Lo anterior es parcialmente correcto, pero se ha mostrado que requiere matices. El estoicismo de Séneca no señala una peculiar y exclusiva resignación hacia la vejez en cuanto tal. La resignación, en tal caso, es reconocer el orden cósmico que nos impulsa a aceptar todas las circunstancias de la vida en cualquier etapa de la misma, sea la juventud, la madurez o la ancianidad.

Séneca da ejemplos de males y fastidios de la vida en la juventud, en la madurez, en la pobreza, la riqueza y, claro está, en la vejez. La sabiduría es lo que debe regir y lo que da el sentido existencial, y no depende en cuanto tal de la edad. La actitud estoica nos muestra que pueden obtenerse unas directrices de racionalidad para enfrentar la vejez: la razón debe regular toda la conducta, para que se vean en su adecuado valor las relaciones con los demás, el afrontamiento de la muerte y los pesares del existir. ${ }^{44}$ De nuevo, esta característica se contrapone con la visión pesimista exagerada de Aristóteles frente al anciano. El anciano, si es verdaderamente sabio, no se deja amedrentar por las vicisitudes de la vida.

Por lo que se ha visto, la categoría de la racionalidad no implica no tomar decisiones «ante el destino», pero no puede sin más adscribirse al concepto de autonomía de nuestro tiempo, ya que Séneca cree que la racionalidad es un reflejo del orden del mundo 
que obedecemos y que no somos creadores de las normas y del valor. No obstante, en el tema del suicido parece asemejarse a nuestro concepto de decidir lo que consideramos bueno. No obstante, como se muestra en los textos analizados, la muerte es concebida como neutra; no es ni buena ni mala, por lo que puede optarse por la misma. Así, el suicidio es permisible porque, en opinión de este filósofo, se cubre el requisito de actuar con plena racionalidad y, como tal, la muerte y la vida no son bienes, son estados en donde se presenta el actuar bien o mal.

En cuanto a una ética del trabajo, se descubre la insistencia de Séneca sobre la importancia del ocio para dedicarse a la filosofía, y critica a los que dejan hasta el final su estudio. Séneca insiste, además, en que es indeseable el morir trabajando. Así, la vejez debe dedicarse a la filosofía, pero no sólo esperarla a ella, ya que la propia filosofía nos prepara para morir bien y vivir bien, y dejarlo al final, cuando además aparecen los inconvenientes de la edad, es una insensatez.

En cuanto a la categoría del tiempo y la finitud, la insistencia de Séneca es vivir bien cada día y no proyectar hacia el futuro nuestras expectativas. El vivir bien no es, entonces, ni acumular honores ni riquezas que, además de ser inestables, alteran el ánimo. La vejez no tiene como meta acumular bienes para disfrutarlos cuando ya pasó la mayor parte de la existencia ante nosotros. Así, en la perspectiva de Séneca, el vivir bien no se equipara a la noción de calidad de vida que se maneja contemporáneamente. Vivir bien es asumir la racionalidad del mundo decretado por Dios y aprender a sobrellevar las carencias o abundancias, manteniendo el ánimo en tranquilidad.

\section{Referencias bibliográficas}

ARISTÓteles. Retórica. Gredos, Madrid, 1999.

DOMINGO, A. Ética y ancianidad: entre la tutela y el respeto. Ética y Ancianidad. Universidad Pontificia Comillas, Madrid, 2009. 
Reflexiones bioéticas acerca de la ancianidad desde el estoicismo de Séneca

Gracia, Diego. Historia de la vejez. Ética y Ancianidad. Universidad Pontificia Comillas, Madrid, 2009.

IACUB, R. La terapéutica estoica con la vejez. Estud. Interdiscip. Envelhec. Porto Alegre, 2009, v. 7.

LÓPEZ, A. La vejez como enfermedad: un tópico acuñado en la antigüedad clásica. Gerokomos. 2018; 29(4): 156-159.

Rodríguez, R. ET AL. Geriatría. McGraw-Hill, México, 2004.

SÉNECA, L. Cartas a Lucilio. Colección Cien del Mundo. SEP, México, 1985.

SÉNECA, L. De brevitate vitae. Moral Essays: volume 2. John W. Basore. London and New York. Heinemann. Perseus digital Library, 1932. Disponible en: https:// www.perseus.tufts.edu/hopper/text?doc=Perseus:text:2007.01.0016

SÉNECA, L. De tranquilitate anime. Moral Essays. 1932; volume 2. John W. Basore. London and New York. Heinemann. Perseus digital Library. Disponible en: http://www.perseus.tufts.edu/hopper/text?doc=Perseus $\% 3 A$ text $\% 3 A 2007$. 01.0021\%3Abook\%3D9\%3Achapter\%3D2

SÉnECA, L. Tratados filosóficos. Porrúa, México, 2016.

\section{Notas bibliográficas}

1 Véase Gracia, DiEgo. Historia de la vejez. En Ética y Ancianidad. Universidad Pontificia Comillas, Madrid, 2009.

${ }^{2}$ Conviene acotar que algunos autores como Galeno no consideraron la vejez como enfermedad, pero sí señalaban que había enfermedades asociadas con la vejez y un verdadero deterioro funcional del anciano. Dicho en términos actuales: reconocían lo que hoy llamamos síndromes geriátricos y la condición de fragilidad del anciano (Rodríguez, R. ET AL. Geriatría. McGraw-Hill, México, 2004).

${ }^{3}$ De hecho, materiales de investigación en torno a la ética y a la vejez en Séneca son pocos, por lo que este trabajo busca llenar en parte ese espacio.

${ }^{4}$ ARISTÓtelEs. Retórica. Gredos, Madrid, 1999, pp. 381-385.

${ }^{5}$ GRACIA, DiEgo. Historia de la vejez, p. 23.

${ }^{6}$ SÉnECA L. Cartas a Lucilio. Colección Cien del Mundo. SEP, México, 1985.

7 SÉnECA, L. Tratados filosóficos. Porrúa, México, 2016. Las referencias de las obras específicas se añaden en el texto entre paréntesis para facilitar la localización en otras ediciones.

${ }^{8}$ SÉnECA, L. Cartas a Lucilio, p. 329.

${ }^{9}$ SÉNECA, L. Cartas a Lucilio, p. 49. Como señala RICARDo IACUB: «...la estrategia estoica es pensar la vejez como un momento en el cual el sujeto se confronta con una falta que probaría la consistencia del sabio y que, por otro lado, permitiría deshacerse de la pesada carga que el cuerpo le produce al alma» (IACUB, R. La terapéutica estoica con la vejez. Estud. Interdiscip. Envelhec. Porto Alegre, 2009, p. 95). Yo agregaría que ese deshacerse no es literal, cosa por demás imposible,

Medicina y Ética - Enero-Marzo 2020 - Vol. 31 - Núm. 1 
sino que, a través del juicio correcto, se valora el alma como el componente racional del hombre que atempera la vida entera.

10 SÉNECA, L. Cartas a Lucilio, p. 49

11 SÉNECA, L. Cartas a Lucilio, p. 89.

12 SÉNECA, L. Tratados filosóficos, p. 74.

${ }^{13}$ SÉNECA, L. Tratados filosóficos, p. 99.

${ }^{14}$ SÉnECA, L. Tratados filosóficos, p. 108.

${ }^{15}$ IACUB, R. La terapéutica estoica con la vejez, p. 97.

${ }^{16}$ SÉnECA, L. Tratados filosóficos, p. 119.

17 Domingo, A. Ética y ancianidad: entre la tutela y el respeto. En Ética y Ancianidad. Universidad Pontificia Comillas, Madrid, 2009, pp. 70-71.

${ }^{18}$ SÉNECA, L. Tratados filosóficos, p. 124.

${ }^{19}$ SÉNECA, L. Tratados filosóficos, p. 181.

20 SÉNECA, L. Cartas a Lucilio, p. 51.

21 SÉnECA, L. Cartas a Lucilio, p. 201.

22 Domingo, A. Ética y ancianidad: entre la tutela y el respeto, p. 79.

${ }^{23}$ SÉnECA, L. Cartas a Lucilio, p. 199.

${ }^{24}$ Naturalmente, lo anterior plantea si Séneca no se pone en entredicho respecto de temas como la pena de muerte y la eutanasia. Según sus postulados, resulta lícito en determinadas circunstancias, pero la duda es cómo compaginar esa idea con la obediencia a lo señalado por Dios como destino del hombre. La pregunta que surge es: ¿Cómo establecer la jerarquía racional entre la autonomía del suicidio y el obedecer lo indicado por Dios como parte de lo que debe ser vivido? No se encontró una respuesta a esa interrogante. De cualquier forma, lo que interesa para fines del artículo, es que el suicidio no se limita sólo a la enfermedad ni a la vejez. Séneca señala, no obstante, que la muerte como tal no es mala, sino sólo el juicio acerca de ella. Entendido así, pudiera argumentase por qué el suicidio no va contra la voluntad divina, ya que no se rechaza un bien dado por ella. Cfr. infra.

${ }^{25}$ Séneca cree que hay normas morales firmes que debemos seguir y que no dependen de nuestras decisiones; por ejemplo, Séneca considera que la sexualidad tiene finalidades reproductivas: "Considera que los deseos del amor no se le han dado al hombre para la voluptuosidad, sino para la propagación de la especie» (Consolación a la madre Helvia, XIII. Tratados filosóficos, p. 82).

${ }^{26}$ SÉnECA, L. Cartas a Lucilio, p. 259.

27 SÉNECA, L. Cartas a Lucilio, pp. 329-330.

${ }^{28}$ SÉnECA, L. Cartas a Lucilio, p. 362.

${ }^{29}$ SÉNECA, L. Cartas a Lucilio, p. 372-373.

30 SÉNECA, L. Tratados filosóficos, p. 126.

${ }^{31}$ SÉnECA, L. Tratados filosóficos, p. 128.

32 SÉNECA, L. Cartas a Lucilio, p. 55.

${ }^{33}$ SÉNECA, L. Cartas a Lucilio, p. 227.

34 SÉnECA, L. Tratados filosóficos, p. 121. "Non pudet te reliquias vitae tibi reservare et id solum tempus bonae menti destinare, quod in nullam rem conferri possit?» De brevitate vitae. Perseus project. Tomado de: https://www.perseus. 
Reflexiones bioéticas acerca de la ancianidad desde el estoicismo de Séneca

tufts.edu/hopper/text?doc=Perseus $\% 3$ Atext $\% 3 A 2007.01 .0016 \% 3 A$ book $\% 3 D 10$ $\% 3 A$ chapter\%3D3

${ }^{35}$ SÉnECA, L. Cartas a Lucilio, p. 367.

${ }^{36}$ SÉNECA, L. Tratados filosóficos, p. 127.

37 SÉnECA, L. Tratados filosóficos, p. 169. «Hanc stabilem animi sedem Graeci euthymian vocant... ego tranquillitatem voco». De tranquilitate animi. Tomado de: http://www.perseus.tufts.edu/hopper/text?doc=Perseus $\% 3 A$ text $\% 3 A 2007$. 01.0021\%3Abook\%3D9\%3Achapter\%3D2

${ }^{38}$ SÉNECA, L. Tratados filosóficos, p. 131.

${ }^{39}$ SÉNECA, L. Tratados filosóficos, p. 130.

40 SÉNECA, L. Tratados filosóficos, p. 132.

${ }^{41}$ SÉnECA, L. Cartas a Lucilio, p. 69.

42 SÉnECA, L. Cartas a Lucilio, p. 29. Y que, por cierto, es fácilmente transferible a nuestro tiempo y el sentido de la vejez y la jubilación: «El problema moral que se plantea con la jubilación no se resuelve retrasando o adelantando la edad con la que se considera jubilado un trabajador. El problema está en la valoración de las personas por el trabajo que realizan, al considerarlas útiles sólo si están "ocupadas" en un trabajo convencional...; la ancianidad es una llamada de atención permanente para no construir una sociedad de necios que confunden valor y precio» (DOMINGo, Ética y ancianidad: entre la tutela y el respeto, p. 72).

${ }^{43}$ SÉNECA, L. Tratados filosóficos, p. 137.

44 «No es más adulto quien demuestra mayor capacidad de ruptura, sino aquel que hace más fecundas sus limitaciones» (DOMINGO, 2009, p. 74). 
